\title{
Оценка эффективности эксплуатации горнотранспортного оборудования
}

Андреева Л.И. ${ }^{1}$, Мусин Р.И. ${ }^{2}$

1 ЧФ ИГД Ур О РАН, Челябинск, tehnorem74@list.ru

20ОО «Бобровский квариит», Магнитогорск, info@bkk-rgk.ru

Аннотация. В статье представлены результаты исследований авторов в направлении оценки эффективности деятельности горнодобывающих предприятий. Рассмотрен системно-комплексный подход к оценке эффективности службы эксплуатации и ремонтного обслуживания горных машин. Приведены факторы, влияющие на эффективность производства, произведен анализ простоев техники, и структуры календарного фонда времени ее использования по назначению и при ремонте. Приведены результаты оценки технического состояния экскаваторов на одном из горнодобывающих предприятий и рекомендации для принятия управленческих решений относительно организации производства. Рассмотрены вопросы стандартизации процессов с позиции регламентации операций ремонтного обслуживания и учетом строгих мер безопасности выполнения работ. Такой подход позволяет выявить скрытые резервы в организационной, технической, технологической и экономической системах.

Ключевые слова: системно-комплексный подход, система учета, материальные и трудовые ресурсы, стандартизация, травматизм.

\section{Effectiveness evaluation of mining-and-transport equipment maintenance}

\author{
Andreeva L. I. ${ }^{1}$, Musin R. I. ${ }^{2}$ \\ ${ }^{1}$ BSF IGD UrORAS, Chelyabinsk, tehnorem74@list.ru \\ ${ }^{2}$ LLC «Bobrovsky quartzite» Magnitogorsk, info@bkk-rgk.ru
}

\begin{abstract}
The article presents the results of the author's research in the direction of effectiveness evaluating of mining enterprises. A system-integrated approach to evaluating the efficiency of the service of operation and maintenance of mining machines is considered. The factors that affect the production efficiency are given, the analysis of equipment downtime, and the structure of the calendar Fund for the time of its use for its intended purpose and during repairs is made. The results of evaluating the technical condition of excavators at one of the mining enterprises and recommendations for making management decisions regarding the organization of production are presented. The issues of standardization of processes from the point of view of regulation of repair maintenance operations and taking into account strict safety measures for work performance are considered. This approach allows you to identify hidden reserves in the organizational, technical, technological and economic systems.

Key words: system-integrated approach, accounting system, material and labor resources, standardization, injuries.
\end{abstract}

\section{Актуальность проблемы}

Материалом для статьи послужили исследования авторов в направлении оценки эффективности эксплуатации горной техники на горнодобывающем предприятии.

Традиционно сложившаяся практика повышения эффективности производства с ориентацией на техническое перевооружение, увеличение единичной мощности оборудования, осуществляемая без должного изменения организации производства, системы планирования ремонтного обслуживания, приводит к неэффективному использованию рабочего времени, при эксплуатации горной техники и оборудования, что в свою очередь, влияет на объемы выпуска конечного продукта (рис. 1).

Изложенная выше ситуация поставила перед собственниками и руководителями горнодобывающих предприятий задачу качественного анализа существующих проблем в целях разработки конкретных решений, обеспечивающих рост производительности труда, повышение эффективности производства и использования горной техники. 


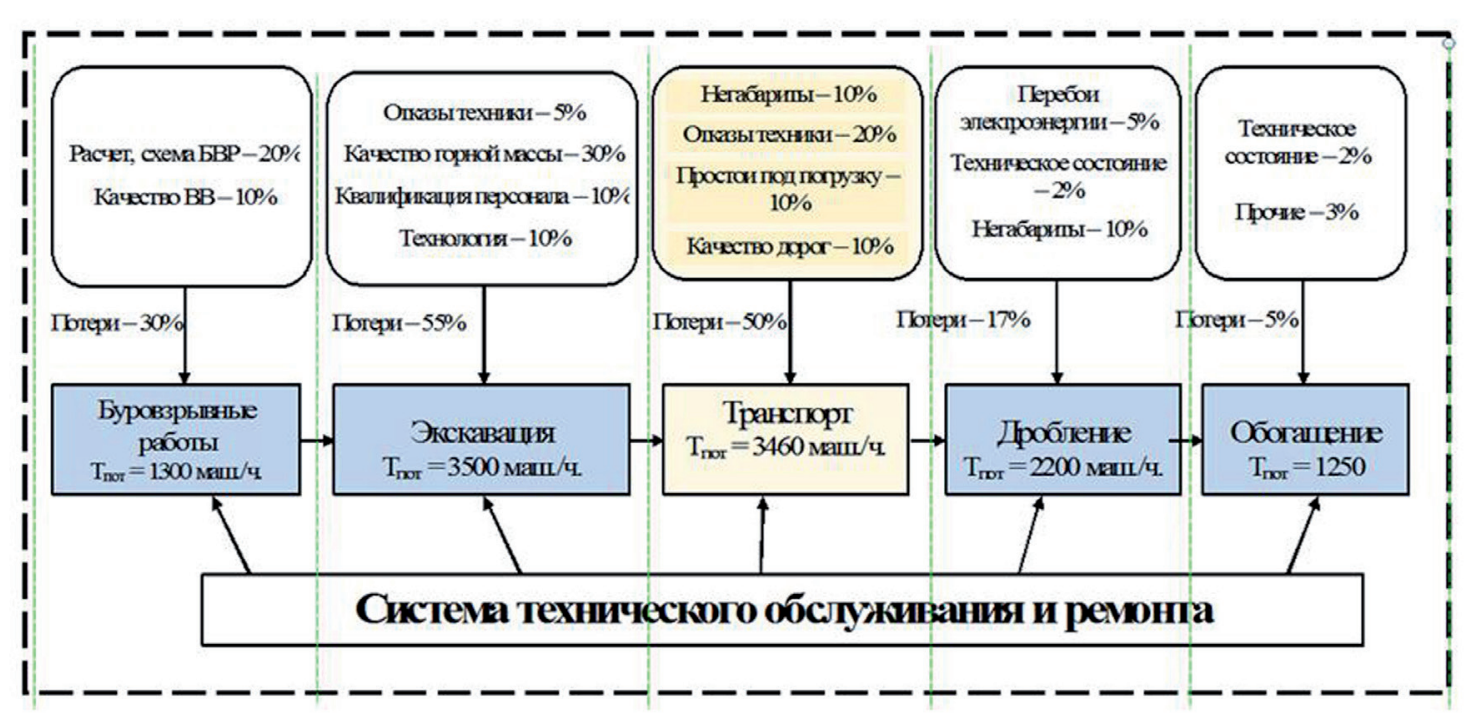

Рис. 1. Потери времени в производственных процессах (исследования 1990-2020 гг.).

Fig. 1. Time loss in production processes (studies 1990-2020).

\section{Методы проведения исследований}

При системно-комплексном подходе к оценке эффективности производства представляется возможным выявить «узкие места» и скрытые резервы в организационной, технической, технологической и экономической системах. (Карпенко и др., 2015; Килин и др., 2019).

Учитывая все сказанное, многие горнодобывающие предприятия, заинтересованные в росте своей эффективности, инициируют проведение производственно-технического аудита по проблемным вопросам с привлечением специалистов сторонних организаций.

Институт эффективности и безопасности горного производства (НИИОГР) имеет достаточно большой опыт проведения подобных работ на предприятиях горной промышленности Якутии, Кузбасса, Казахстана, Северо-западном регионе России по направлениям: оценка организационнотехнической системы ремонтного производства (ремонтные мощности); оценка целесообразности эксплуатации горнотранспортного оборудования по соотношению «результаты-затраты»; определение очередности вывода техники из эксплуатации; исследование структуры и эффективности использования ремонтного персонала; оценка взаимодействия структурных подразделений предприятия; оценка влияний режимов и условий эксплуатации на производительность горной техники; стандартизация процессов.

\section{Результаты исследования}

Выполненные исследования позволили установить, что на эффективность производства влияют факторы, как со стороны эксплуатации, так и со стороны ремонтного обслуживания горной техники (рис. 2).

Как показывает практика качество, продолжительность и себестоимость обслуживания горной техники определяется технологией и организацией ремонтного производства. В зависимости от формы и уровня организации, технологии технического обслуживания и ремонта, различия в расходе запасных частей на 1 маш.-ч. эксплуатации экскаваторов составляют 2.0-3.5 раза.

Анализ простоев горного оборудования выявил, что из 8760 часов календарного фонда времени (КФВ) плановые и простои по отказу техники составили соответственно 37 \% и $24 \%$. По расчетам на 1 час планового простоя приходится 0.2-3.0 часа простоев по отказу.

Современные горные машины эксплуатируются в тяжелых условиях, связанных с ограниченностью габаритов, абразивностью горных пород, высокой запыленностью, воздействием агрессивных шахтных вод. Это оказывает существенное влияние на их работу. Так, при эксплуатации горной техники при низких температурах параметр потока отказов увеличивается в 2.2-2.3 раза, а ко- 


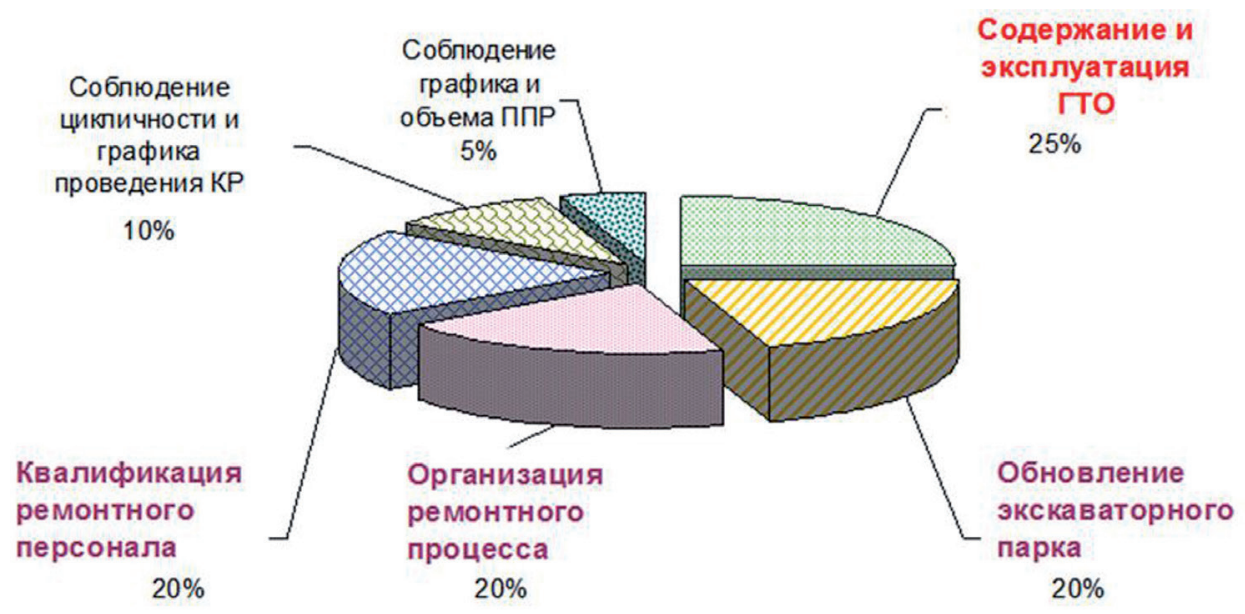

Рис. 2. Факторы, влияющие на эффективность производства.

Fig. 2. Factors affecting production efficiency.

эффициент технического использования снижается в 1.6-2.4 раза. В таких условиях значительно интенсифицируется старение машин и, соответственно, снижается их функциональный ресурс (Robert J House и др.; Боярских и др., 2004).

Зачастую, техническим службам горнодобывающих предприятиям сложно перейти от традиционно сложившейся стратегии плановых ремонтов и ремонтов по отказам к стратегии профилактики отказов, основанной на систематическом мониторинге технического состояния горных машин и оборудования.

Моделирующий семинар - практикум, проведенный в ООО «Бобровский кварцит» дал возможность персоналу предприятия определить этапы перехода от аварийных ремонтов к стратегии профилактики отказов (рис. 3).

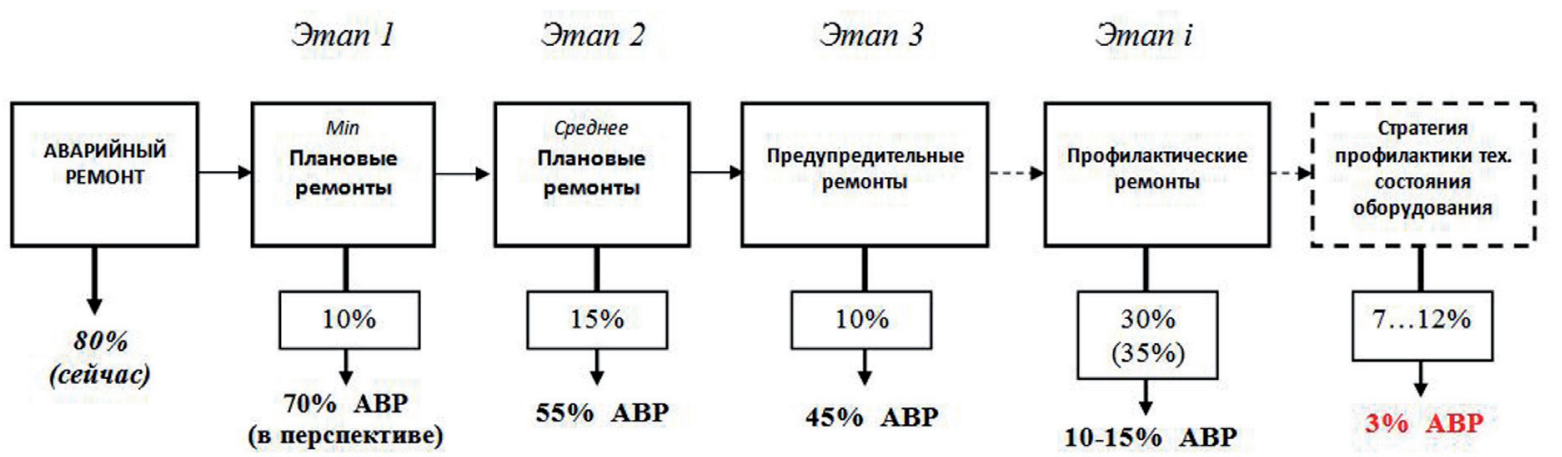

Рис. 3. Схема перехода от ремонтов по отказу к стратегии профилактики.

Fig. 3. Scheme of transition from repairs on failure to the prevention strategy.

Роль использования стратегии профилактики отказов горной техники в настоящее время возросла в силу следующих причин: увеличились затраты, связанные с содержанием и обслуживанием техники, эксплуатируемой в экстремальных условиях; парк горной техники и оборудования имеет значительный моральный и физический износ, что предопределяет его частичную замену, либо дорогостоящий ремонт.

Что в этом случае позволит предприятию снизить затраты на ремонтное обслуживание и сократить до минимума простои? Достичь этого возможно за счет нескольких факторов:

ведение учета оборудования, «историй» всех проводимых ремонтных работ. Без учета невозможно проведение анализа результатов эксплуатации, причин возникновения дефектов, эффективности инвестиций; введение нормирования ремонтных работ, вплоть до операций. Введение норм невозможно без налаженной системы учета. 
Если на предприятии не отлажена система учета и планирование осуществляется «в ручном режиме», то график ремонта техники является формальным, не привязанным к реальным условиям эксплуатации. (Андреева, 2015)

По результатам ревизии техники, опроса руководителей технических служб, специалистов и анализа отчетных данных были выявлены факторы, определяющие существующее неудовлетворительное состояние горного оборудования: существенные отклонения (15-35 \%) от графиков ремонта при проведении капитальных и средних ремонтов, профилактических работ; низкое качество выполняемых ремонтов (по оценкам службы, эксплуатирующей горную технику); отсутствие контроля за соблюдением режимов эксплуатации горной техники в соответствии с паспортом (оборудования, забоя и пр.).

Результаты оценки технического состояния экскаваторов на одном из горнодобывающих предприятий Казахстана приведены в таблице 1.

Таблица 1. Техническое состояние экскаваторов.

Table 1. Technical condition of excavators.

\begin{tabular}{|c|c|c|c|c|}
\hline \multirow{2}{*}{ Карьер } & \multirow{2}{*}{$\begin{array}{l}\text { Кол-во } \\
\text { единиц }\end{array}$} & \multicolumn{3}{|c|}{ Оценка технического состояния } \\
\hline & & Удовлетворительное & Неудовлетворительное & Аварийное \\
\hline «Карьер 1» & 18 & №№ 103, 201, 137, 207 & $\begin{array}{c}\text { №№ } \begin{array}{c}38,112,104,119,117,136, \\
140,127,114,142,143\end{array}\end{array}$ & $\begin{array}{c}\text { №№ } 141,139- \\
\text { осмотрены дважды, } \\
\text { № } 122\end{array}$ \\
\hline «Карьер 1а» & 3 & №№ 204, 205, 208 & - & - \\
\hline «Карьер 3» & 8 & № 69 & №№ $113,75,83,123,71,77,91$ & - \\
\hline «Карьер 2» & 26 & $\begin{array}{c}\text { №№ } 51,44,65,66,55,07 \text {, } \\
09,18,02,58,59,39,10, \\
16\end{array}$ & $\begin{array}{l}\text { №№ } 03,56,38,05,23,19,46,20 \text {, } \\
61,17, \text { № } 62 \text { - осмотрен дважды }\end{array}$ & № 36 \\
\hline «Карьер 4» & 9 & № 7 & $\begin{array}{c}\text { №№ } 10,39,65,66,68,125,132, \\
197\end{array}$ & - \\
\hline Всего & 64 & 23 & 37 & 4 \\
\hline
\end{tabular}

\section{По результатам обследования экскаваторов было рекомендовано:}

1. В рамках проведения профилактического обслуживания экскаваторов составить график контроля технического состояния узлов и агрегатов, персонифицировать ответственность за его выполнение.

2. Определить техническое состояние каждого экскаватора (экспертно, инструментально, с помощью приборов).

3. Составить графики периодичности и продолжительности, определить содержание ежесменного и ежемесячного технического обслуживания экскаваторов. Ответственность за их выполнением закрепить за экипажем.

4. Разработать инструкцию контроля качества ремонтных работ, проводимых силами ремонтных бригад.

5. Проверить укомплектованность ремонтных бригад инструментом, оснасткой и комплектующими.

6. Провести ревизию (наличие и качество) требуемой технической документации (регламентов ТО, Т1) на каждом экскаваторе. При необходимости укомплектовать.

7. Организовать контроль состояния забоя, режимов и условий эксплуатации (экипаж).

\section{Прогноз развития}

Для повышения уровня эффективности эксплуатации горной техники и использования имеющихся ресурсов приоритетной задачей должна стать стандартизация производственных операций и процессов, которая регламентирует время производительной работы техники и стоимость обеспечения работоспособности оборудования. 
Необходимым условием решения этой задачи является паспортизация оборудования, позволяющая вести учет данных по каждой единице техники (техн. характеристики, состояние, расход материалов и запчастей, статистику отказов, плановость ТО и ремонта, стоимость обслуживания и т.д.).

Потребность в ресурсах ремонтного производства должна быть основана на оценке экономической целесообразности проведения ремонтов каждой единицы техники, персонифицированной ответственности за использование ресурсов на рабочем месте, участке, цехе, на формировании системы экономических отношений между службами технической и производственной эксплуатации горной техники и оборудования.

Одним из важнейших аспектов повышения эффективности производства является контроль уровня безопасности процессов и персонала занятого на технологических операциях. Собственники предприятий вынуждены значительно увеличивать финансирование мероприятий по обеспечению безопасности производства, проводить организационные изменения - и, тем не менее, имеют экономические потери вследствие как остановок производства, так и выхода из строя оборудования из-за аварий и инцидентов даже если они не сопровождаются человеческими жертвами.

Проведенные исследования показали, что на Российских угледобывающих предприятиях, оснащенных самой современной техникой, уровень тяжелого и смертельного травматизма выше, чем на таких же зарубежных в 1.2-1.3 раза на 1000 трудящихся и в 2.0-2.5 раза - на 1 млн. т добываемого угля, при этом риск травмирования персонала выше в 5-7 раз. Фоновый (естественный) риск, обусловленный свойствами массивов пород и параметрами применяемого оборудования, вполне сопоставим. Риск же, обусловленный организацией производства, на российских угледобывающих предприятиях выше на полтора порядка (35-70 раз). (Артемьев и др., 2010; Ковалев, 2009).

Такая ситуация сложилась вследствие несоблюдения технологических регламентов, обусловленного недостаточным уровнем организации производства. По данным Ростехнадзора, остановки производства после инцидентов, аварий, тяжелых и смертельных травм, групповых несчастных случаев сопровождаются экономическими потерями, в 50-100 раз превышающими размер своевременных затрат на предотвращение негативных последствий этих событий. Более глубокий и тщательный анализ показывает, что значение этих показателей на 2-3 порядка выше. (Ковалев, 2009).

\section{Заключение}

1. Проведение производственно-технического аудита на предприятиях: «УК «Кузбассразрезуголь», УК «АЛРОСА» (ЗАО), АО «Соколовско-Сарбайское горно-обогатительное производственное объединение» и АО «Евроазиатская Энергетическая Корпорация» (Республика Казахстан), АО «Ковдорский ГОК» с использованием системно-комплексного подхода оценки эффективности производства позволило выйти предприятиям на следующие результаты, представленные в таблице 2.

2. После завершения работ по оценке эффективности деятельности горнодобывающих предприятий им переданы методические материалы, Положения о ППР, ремонтно-технологическая и нормативная документация, методики и методические рекомендации, содержащие аналитические расчеты, позволяющие при соответствующей организации и заинтересованности ключевого персонала предприятия выйти на другой уровень эффективности, посредством оптимизации расхода ресурсов и повышения надежности горной техники.

Кратко обобщая результаты проведенного исследования, важно обратить внимание на необходимость постоянного совершенствования методов расчетов и оценки деятельности горнодобывающего предприятия, что позволит своевременно реагировать на негативные изменения и принимать соответствующие управленческие решения. 
Таблица 2. Результаты деятельности горнодобывающих предприятий.

Table 2. Mining companies ' performance results.

\begin{tabular}{|c|c|c|}
\hline Экскавация & Рудоподготовка & Обогащение \\
\hline $\begin{array}{l}\text { принято решение о выводе части } \\
\text { горной техники из эксплуатации } \\
\text { по критериям: } \\
\text { - надежность; } \\
\text { - интенсивность } \\
\text { - экономичность. }\end{array}$ & $\begin{array}{l}\text { произведена оценка техническо- } \\
\text { го состояния и производитель- } \\
\text { ности дробильно-размольного } \\
\text { оборудования (ДРО) }\end{array}$ & $\begin{array}{l}\text { произведен расчет возможной про- } \\
\text { изводительности обогатительного } \\
\text { оборудования }\end{array}$ \\
\hline $\begin{array}{l}\text { разработано пять проектов эф- } \\
\text { фективной организации работ } \\
\text { ремонтных участков }\end{array}$ & $\begin{array}{l}\text { разработаны рекомендации по } \\
\text { замене ДРО с учетом его техни- } \\
\text { ческого состояния и производи- } \\
\text { тельности }\end{array}$ & $\begin{array}{l}\text { проведена оценка знаний эксплуа- } \\
\text { тационного и ремонтного персона- } \\
\text { ла относительно его функционала }\end{array}$ \\
\hline $\begin{array}{l}\text { разработаны технологические } \\
\text { регламенты на ремонт экскавато- } \\
\text { ров (стандарты) }\end{array}$ & $\begin{array}{l}\text { разработаны технологические } \\
\text { регламенты на ремонт ДРО }\end{array}$ & $\begin{array}{l}\text { проведены аналитико- } \\
\text { моделирующие семинары по во- } \\
\text { просам мотивации, взаимодей- } \\
\text { ствия персонала }\end{array}$ \\
\hline $\begin{array}{l}\text { проведена аттестация машини- } \\
\text { стов экскаваторов }\end{array}$ & $\begin{array}{l}\text { проведены учебные семинары } \\
\text { по освоению персоналом техни- } \\
\text { ческих регламентов }\end{array}$ & $\begin{array}{l}\text { разработаны технологические ре- } \\
\text { гламенты на ремонт обогатитель- } \\
\text { ного оборудования }\end{array}$ \\
\hline $\begin{array}{l}\text { проведена аттестация ремонтно- } \\
\text { го персонала }\end{array}$ & $\begin{array}{l}\text { проведена проверка знаний ре- } \\
\text { монтного и эксплуатационного } \\
\text { персонала относительно знаний } \\
\text { по техники безопасности }\end{array}$ & $\begin{array}{l}\text { проведен хронометраж рабочего } \\
\text { времени руководителями и специ- } \\
\text { алистами цеха. Выявлены потери } \\
\text { рабочего времени }-35 \%\end{array}$ \\
\hline $\begin{array}{l}\text { разработаны маршрутные карты } \\
\text { осмотра горной техники и обору- } \\
\text { дования (чек-листы) }\end{array}$ & $\begin{array}{l}\text { разработано «Положение о взаи- } \\
\text { модействии подразделений» }\end{array}$ & $\begin{array}{l}\text { проведен хронометраж рабоче- } \\
\text { го времени ремонтного персонала. } \\
\text { Выявлены потери рабочего време- } \\
\text { ни - } 30 \%\end{array}$ \\
\hline $\begin{array}{l}\text { разработано Положение о моти- } \\
\text { вации эксплуатационного и ре-- } \\
\text { монтного персонала }\end{array}$ & $\begin{array}{l}\text { разработано «Положение о мо- } \\
\text { тивации персонала» }\end{array}$ & \\
\hline
\end{tabular}

\section{Литература}

8. Андреева Л.И. Возможности повышения эффективности использования ресурсов в ремонтном производстве // Проблемы недропользования. Екатеринбург. Изд-во: ИГД УрО РАН. 2015. Вып. 1(4). C. $134-141$.

9. Артемьев В.Б. Сальников А.А., Заньков А.П. и др. Эффективность и безопасность производства с точки зрения экономики: противоречие или единство? М. Изд-во: Горная книга. 2010. Вып. 9.32 с.

10. Боярских Г.А. и др. Теория старения машин. Екатеринбург. 2004. 186 с.

11. Карпенко С.В., Емец И.И., Харитонов Ю.А., Андреева Л.И., Красникова Т.И. Повышение эффективности организации деятельности ремонтной службы как важная составляющая функционала главного механика // Уголь. 2015. № 1. С. 66-68.

12. Килин А.Б., Азев В.А., Костарев А.С., и др. Эффективное развитие угледобывающего производственного объединения: практика и методы (под. ред В.Б. Артемьева). М. Изд-во: Горная книга. 2019. 280 с.

13. Ковалев В.А. Методология развития региональной системы управления охраной труда и промышленной безопасностью на угольных шахтах: Дисс. д.т.н.: 05.26.01. / В.А. Ковалев. М. 2009. 301 с.

14. Robert J House, Andre Delbecg, Toon W. Taris. Value Dased Leadership: An Integrated Theory and an Empirical Test (working paper). 